\title{
15-year developmental study on effects of severe undernutrition during infancy on subsequent physical growth and intellectual functioning
}

\author{
M. B. STOCH and P. M. SMYTHE \\ From the Child Psychiatric Unit and Department of Paediatrics and Child Health, University of Cape \\ Town, South Africa
}

\begin{abstract}
Stoch, M. B., and Smythe, P. M. (1976). Archives of Disease in Childhood, 51, 327. 15-year developmental study on effects of severe undernutrition during infancy on subsequent physical growth and intellectual functioning. This third 5-year follow-up on the effects of severe undernutrition during infancy on subsequent brain growth and intellectual development confirms the level of gross retardation of intellect in the undernourished group when compared with the controls. A.s the subjects are now 15-18 years of age this must be permanent. All but 5 of the undernourished group are now living in conditions comparable to the controls. Improved nutrition is manifest by catch-up in height, in that the mean difference between undernourished subjects and controls has decreased by $2 \cdot 73 \mathrm{~cm}$. Remarkably, the difference in head circumference has increased by $0.5 \mathrm{~cm}$, the mean head circumference of the undernourished now being $2.8 \mathrm{~cm}$ less than that of the controls. The Bender Gestalt and Human Figure Drawing tests did not correlate with the intelligence tests, indicating a separate deficit of a marked disturbance of visual-motor perception in 17 of the undernourished subjects, in 9 of whom these tests were highly significant of minimal brain dysfunction ( 5 of the controls). In retrospect there is much evidence to suggest the controls were also suboptimal; 8 controls had abnormal electroencephalograms as did 6 of the undernourished group.
\end{abstract}

This study was started in 1955 , based on the hypothesis that the ill effects of undernutrition are determined firstly by its occurrence during the period of maximum growth and, secondly, by the duration of undernutrition relative to the total period of growth. As brain growth in the human is very rapid during the first year of life and almost complete by the end of the second year it seemed possible that undernutrition during this critical period might inhibit brain growth and that this could result in a permanent reduction in brain size and impaired intellectual development.

To test this hypothesis a group of subjects grossly undernourished during early infancy was compared with a control group. Two previous reports on this study were published in 1963 and 1967 (Stoch and Smythe). This third 5-year study is of particular value as little further develop-

Received 7 August 1975. mental change is likely to occur in these now adolescent subjects and the information gained from agedependent tests can be interpreted with greater validity.

\section{Subjects}

A group of 20 coloured infants, 9 boys and 11 girls, grossly undernourished during infancy, from Cape Town was collected over the period 1955 to 1959 . This index group was contrasted with a control group, matched for age and sex, selected from a crêche-cum-nursery school serving a subpopulation of the same social class as the index group. Organic illness, apart from intercurrent gastroenteritis, was absent in the infants. When first seen their mean weight was $5.53 \mathrm{~kg}$ at 17 months (boys 5.44 at 19 months, girls 5.61 at 15.5 months), which was below the 2.5 centile (Robertson, 1961). The mean weight of $8.16 \mathrm{~kg}$ of the control infants (boys $8.9 \mathrm{~kg}$ at 18 months, girls $8.8 \mathrm{~kg}$ at 17 months) was at the 10th centile. Both groups came from the lower social class unskilled workers with low incomes. 
There was at first a marked disparity in their living conditions, with the index group at a distinct disadvantage. The home environment except in the case of 5 index subjects, is now barely distinguishable because of greater economic stability and foster placements.

\section{Method}

The present follow-up was undertaken between February 1972 and May 1973 when the average age of the subjects was 16 years (range $13 \cdot 7-18 \cdot 2$ years. Each subject was tested on one or more occasions and each parent or guardian was interviewed. Measurements of head circumference, height, and weight were made. General intelligence was measured with the New South African Individual Scale (NSAIS) (National Bureau of Education and Social Research, 1964). This test, which resembles the Wechsler Intelligence Scale for Children, has not been standardized for the population group of this study but the findings were considered valid for assessing differences between the two groups. Visual-motor perception was measured on the Bender Visual-Motor Gestalt Test (BG), (Koppitz, 1964). Body concept was assessed on the Human Figure Drawing (HFD) (Koppitz, 1968). Social integration was assessed on the Columbus, a projective test (Langeveld, 1969). Psychosocial histories were also taken. Electroencephalograms and skull $x$-rays were done at the Red Cross War Memorial Children's Hospital.

\section{Results}

Comparisons were made of the means of the index and control groups $(n=40)$ and the subgroups of boys $(n=18)$ and girls $(n=22)$.
Physical measurements. The difference in head circumference for both boys and girls is highly significant (Table I). There is no significant difference in height or weight between the two groups of boys but the girls differ significantly in both these measurements. As the only physical measurement in which the boys differ is head circumference, it appears that catch-up in their somatic growth has been achieved but smaller head circumference is permanent. In contrast, the girls' groups have maintained a difference in all physical measurements.

Psychological tests. The difference of $16 \cdot 85$ full scale points between the groups is significant (Table II). This difference is most marked between the boys $(24 \cdot 55)$. The much smaller difference between the girls is due to the low score of the control girls, which is 13.6 points lower than the control boys.

The verbal quotient follows a pattern similar to the full scale quotient. There is a significant difference between the groups $(17 \cdot 50)$, a marked difference between the boys $(25 \cdot 10)$, and a much smaller difference between the girls $(11 \cdot 27)$ which is again due to the lower score of the control girls. The difference of 17.06 points between the control boys and control girls is significant at the 0.05 level. In the non-verbal quotient the groups also differ significantly $(14 \cdot 3)$ though the difference is more marked for boys $(19 \cdot 89)$ than girls $(9 \cdot 72)$. In the index group there is no difference between boys

TABLE I

Physical measurements

\begin{tabular}{|c|c|c|c|c|c|c|c|c|c|}
\hline & \multicolumn{3}{|c|}{ Group } & \multicolumn{3}{|c|}{ Boys } & \multicolumn{3}{|c|}{ Girls } \\
\hline & Index & Control & $\mathbf{P}$ & Index & Control & $\mathbf{P}$ & Index & Control & $\mathbf{P}$ \\
\hline $\begin{array}{l}\text { Head circumference } \\
\quad \text { (cm) } \\
\text { Height (cm) } \\
\text { Weight (kg) }\end{array}$ & $\begin{array}{r}51 \cdot 71 \\
153 \cdot 11 \\
42 \cdot 95\end{array}$ & $\begin{array}{r}54 \cdot 51 \\
159 \cdot 18 \\
48 \cdot 30\end{array}$ & $\begin{array}{l}<0.005 \\
<0.05 \\
<0.05\end{array}$ & $\begin{array}{r}51 \cdot 77 \\
157 \cdot 89 \\
44 \cdot 57\end{array}$ & $\begin{array}{r}55 \cdot 24 \\
164 \cdot 54 \\
49 \cdot 42\end{array}$ & $\begin{array}{l}<0.005 \\
\text { NS } \\
\text { NS }\end{array}$ & $\begin{array}{r}51 \cdot 66 \\
149 \cdot 20 \\
41 \cdot 63\end{array}$ & $\begin{array}{r}53 \cdot 98 \\
154 \cdot 81 \\
47 \cdot 38\end{array}$ & $\begin{array}{l}<0.005 \\
<0.005 \\
<0.05\end{array}$ \\
\hline
\end{tabular}

TABLE II

New S. African Individual Scale (quotients)

\begin{tabular}{|c|c|c|c|c|c|c|c|c|c|}
\hline \multirow{2}{*}{ Quotient } & \multicolumn{3}{|c|}{ Group } & \multicolumn{3}{|c|}{ Boys } & \multicolumn{3}{|c|}{ Girls } \\
\hline & Index & Control & $\mathbf{P}$ & Index & Control & $\mathbf{P}$ & Index & Control & $\mathbf{P}$ \\
\hline $\begin{array}{l}\text { Full scale } \\
\text { Verbal } \\
\text { Nonverbal }\end{array}$ & $\begin{array}{l}56 \cdot 00 \\
55 \cdot 00 \\
65 \cdot 60\end{array}$ & $\begin{array}{l}72 \cdot 85 \\
72 \cdot 50 \\
79 \cdot 90\end{array}$ & $\begin{array}{l}<0.005 \\
<0.005 \\
<0.005\end{array}$ & $\begin{array}{l}55 \cdot 78 \\
56 \cdot 78 \\
63 \cdot 00\end{array}$ & $\begin{array}{l}80 \cdot 33 \\
81 \cdot 88 \\
82 \cdot 89\end{array}$ & $\begin{array}{l}<0.005 \\
<0.005 \\
<0.005\end{array}$ & $\begin{array}{l}56 \cdot 18 \\
53 \cdot 55 \\
67 \cdot 73\end{array}$ & $\begin{array}{l}66 \cdot 73 \\
64 \cdot 82 \\
77 \cdot 45\end{array}$ & $\begin{array}{l}<0.05 \\
<0.05 \\
<0.05\end{array}$ \\
\hline
\end{tabular}


and girls in all three quotients. In both groups of girls there is a significant difference between the verbal and nonverbal quotients (Table III), the nonverbal being higher.

TABLE III

Differences between verbal and nonverbal quotients within subgroup

\begin{tabular}{l|c|c}
\hline \multicolumn{1}{c|}{ Subgroup } & Difference & P \\
\hline Control boys & $1 \cdot 01$ & NS \\
Index boys & $6 \cdot 22$ & NS \\
Control girls & 12.63 & $<0.05$ \\
Index girls & 14.18 & $<0.01$ \\
\hline
\end{tabular}

Subtests. In the statistical analysis of the subtests of the NSAIS (Table IV) the control boys surpassed the index in all the verbal tests in contrast with both groups of girls, who did not differ in the important subtests of vocabulary and verbal reasoning.

In the non-verbal subtests of pattern completion and blocks the boys and girls within each group differed significantly.

Bender Visual-Motor Gestalt test. The ability to copy geometric designs is a reflection of the maturity of visual-motor perception. Up to the age of 11 years errors indicate either perceptual immaturity or a defect in neurological functioning. By 11 years the development of visual-motor perception is complete and significant errors can only reflect impaired neurological function (Bender, 1938 Koppitz, 1964).

The index group made an average of 3.65 errors (Table V) at the age of 16 , which suggests a deficit in their visual-motor perception, seeing that ample time has been allowed for maturational lag. The index boys made more errors than the girls, the only measurement in which the sexes of this group differ significantly $(P<0.05)$. The errors were scrutinized for indications of minimal brain dysfunction (MBD) as described by Koppitz (1964) in children ranging in age from 5-11 years. 3 of the index group made no errors and 9 ( 5 boys, 4 girls) made 21 errors, highly significant for MBD. 10 of the controls made no errors, while 5 subjects, all girls, made 8 errors, highly significant for MBD. 7 index subjects had a perceptual age below 7 years. whereas the lowest control's was $7 \cdot 75$ years.

Human Figure Drawing. The HFD was selected as it provides a measure of developmental maturity, awareness of the body in space, and relation of one part to another-skills which have strong implica-

\section{TABLE IV}

Differences in new $S$. African Individual Scale subtests ( $P$ values)

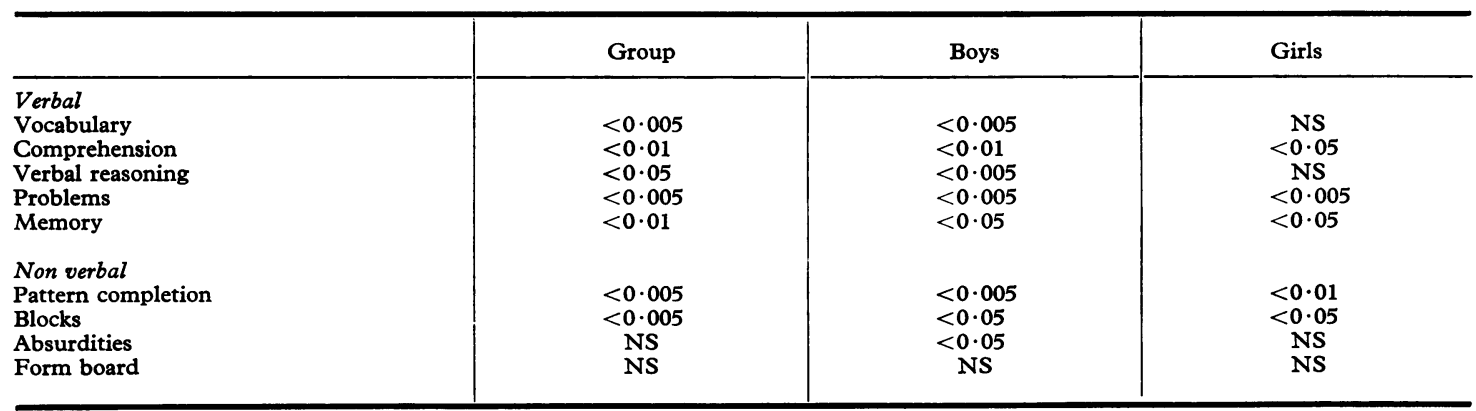

TABLE V

Bender Visual-Motor Gestalt test

\begin{tabular}{|c|c|c|c|c|c|c|}
\hline & \multicolumn{2}{|c|}{ Group } & \multicolumn{2}{|c|}{ Boys } & \multicolumn{2}{|c|}{ Girls } \\
\hline & Index & Control & Index & Control & Index & Control \\
\hline $\begin{array}{l}\text { Errors } \\
\mathbf{P}\end{array}$ & $3 \cdot 65$ & $0 \cdot 85$ & $4 \cdot 22$ & $0 \cdot 67$ & $3 \cdot 18$ & $1 \cdot 0$ \\
\hline
\end{tabular}


TABLE VI

Human Figure Drawing

\begin{tabular}{|c|c|c|c|c|c|c|}
\hline & \multicolumn{2}{|c|}{ Group } & \multicolumn{2}{|c|}{ Boys } & \multicolumn{2}{|c|}{ Girls } \\
\hline & Index & Control & Index & Control & Index & Control \\
\hline $\begin{array}{l}\text { Maturity rating } \\
\mathbf{P} \text { Value }\end{array}$ & \multicolumn{2}{|c|}{$<0.005$} & \multicolumn{2}{|c|}{$<0.05$} & \multicolumn{2}{|c|}{$<0.05$} \\
\hline
\end{tabular}

tions for body concept. Subjects were requested to draw a person and name the sex, then to draw the other sex. In Table VI a score of 5 represents average developmental maturity (Koppitz, 1968). The HFD scores of the control groups are significantly superior.

Ten HFD's of the index group ( 5 boys, 5 girls) are strongly indicative of organic deficits in contrast to 6 ( 3 boys, 3 girls) controls $(P<0.01)$. Because of the subjects' advanced ages the distortions in their drawings were considered highly significant. Projective evidence of emotional disturbance and poor sex identification were noted in both groups but not quantified as scoring was too subjective. In the index group there was a significant correlation between HFD and BG $(r=0 \cdot 7)$. This suggests that the perceptual deficit which they

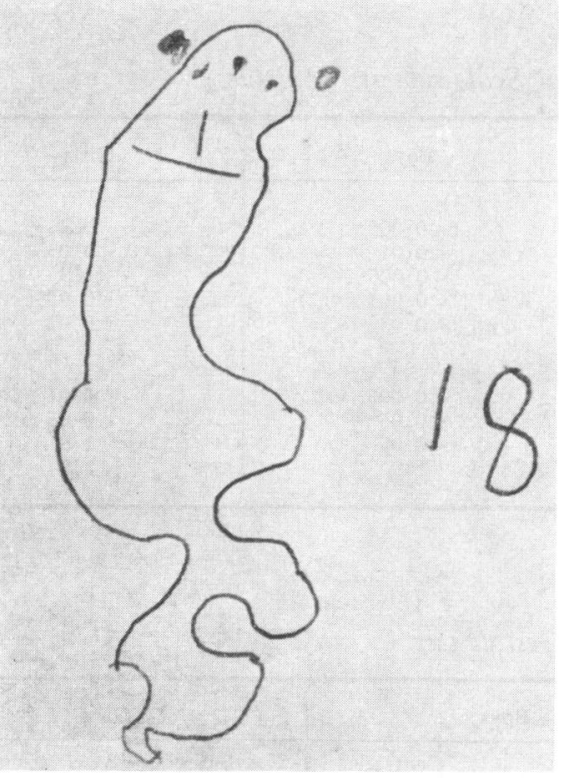

(a) are experiencing is linked to the field of spacial relations. The extreme distortion in visual-motor perception and body concept can be seen in the BG and HFD of some of the index subjects (Figs. 1-4).

The lack of any correlation between the BG and the NSAIS quotients in the index group suggests a specific perceptual disability apart from their poor intelligence test performance. Table VII shows how in children of matched intelligence quotients the developmental level differs in their BG and in two of their HFDs.

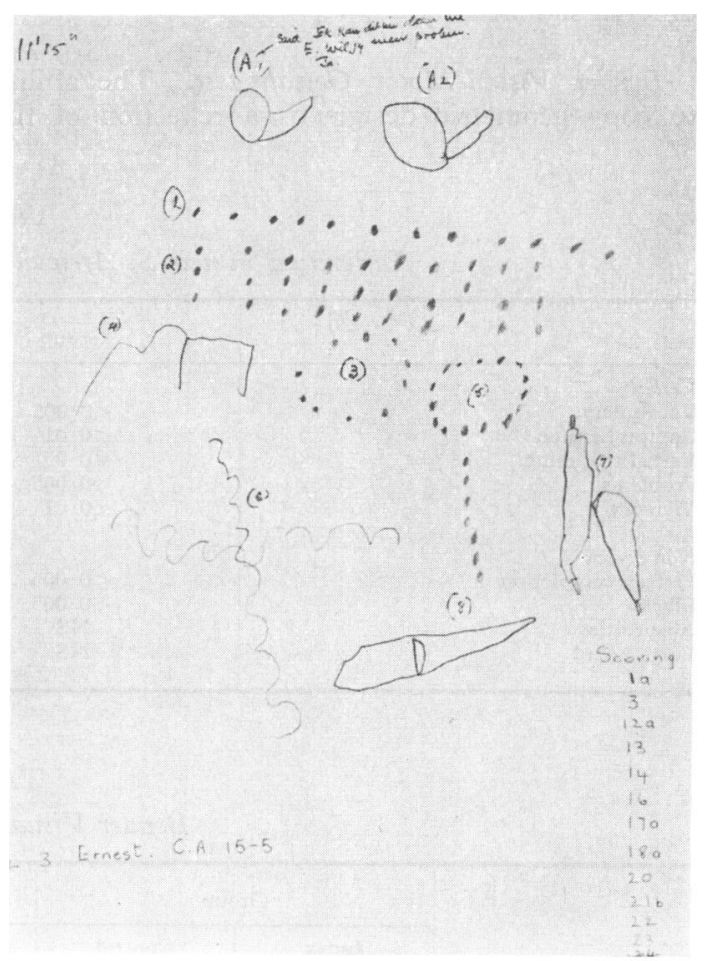

(b)

Fig. 1.-Index subject. (a) Human figure drawing. (b) Bender Gestalt. 


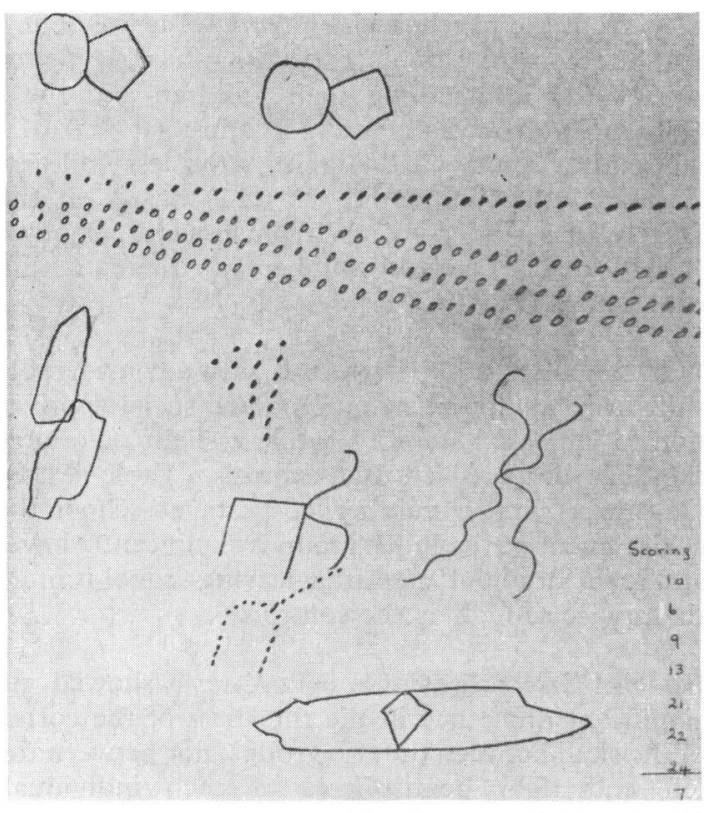

(a)

motives, and strength of identity. In scoring, the composite total in these four areas represents the subject's emotional and social maturity or social integration. The control group was significantly superior $(P<0 \cdot 05)$.

Psychosocial findings. In view of the importance of sociocultural influences on intellectual development, the changes which have occurred over the past 15 years have been assessed. Here again

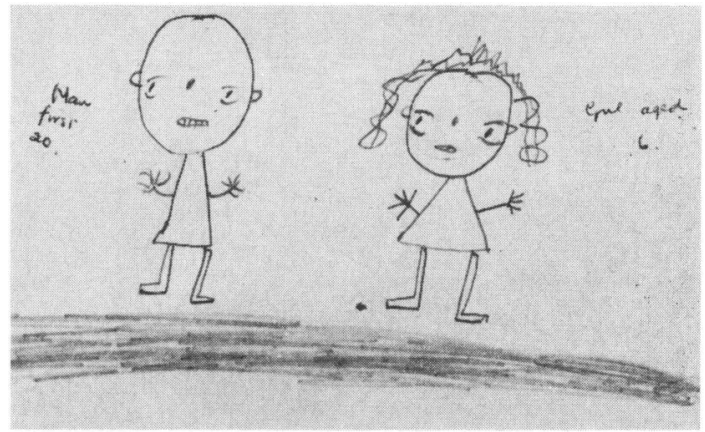

(b)

Fig. 2.-Index subject. (a) Bender Gestalt. (b) Human figure drawing.

Columbus test. In this projective test verbal responses to stimulus cards were rated for four aspects of social personality: interpersonal relationships, attitude towards the future, maturity of not only were group findings contrasted, but within each group the sexes were contrasted. At present there are no significant differences in socioeconomic status or housing between the two groups. How-

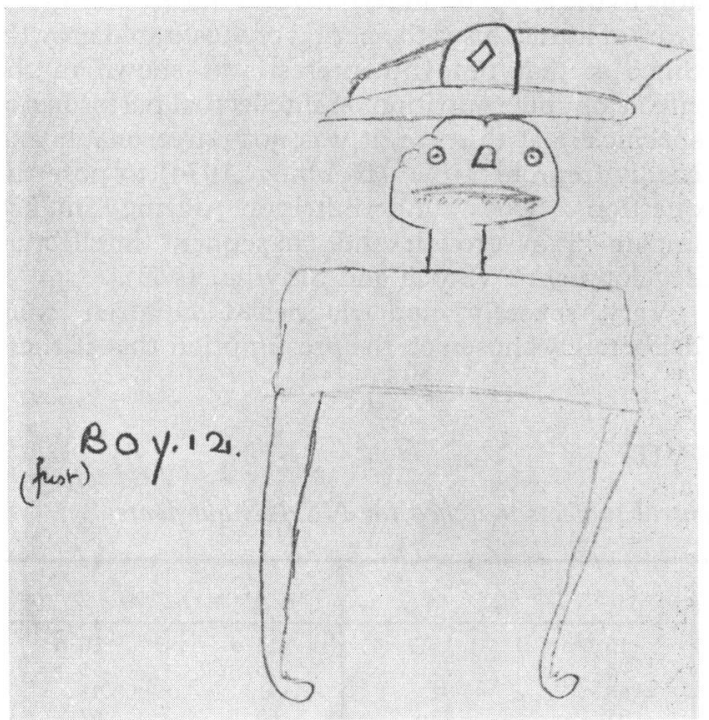

(a)

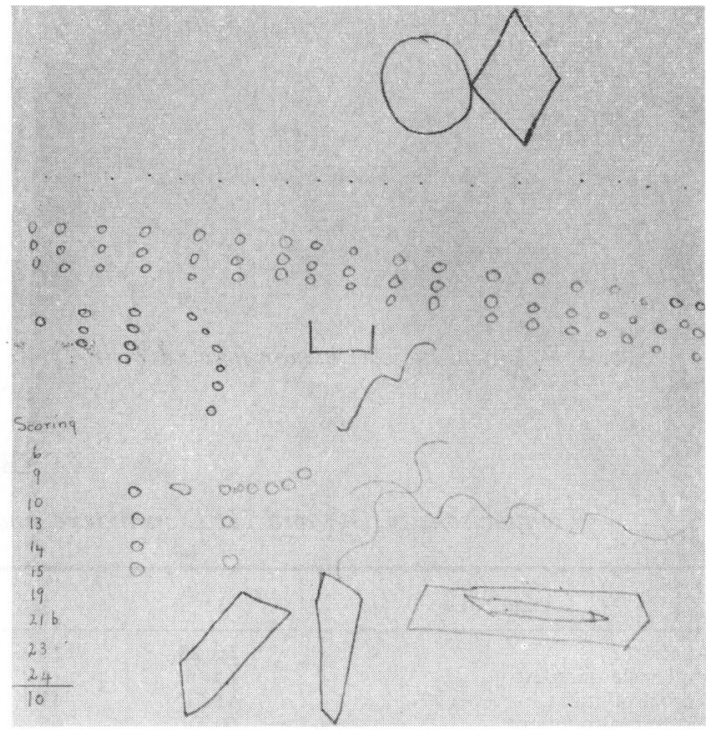

(b)

FIG. 3.-Index subject. (a) Human figure drawing. (b) Bender Gestalt. 


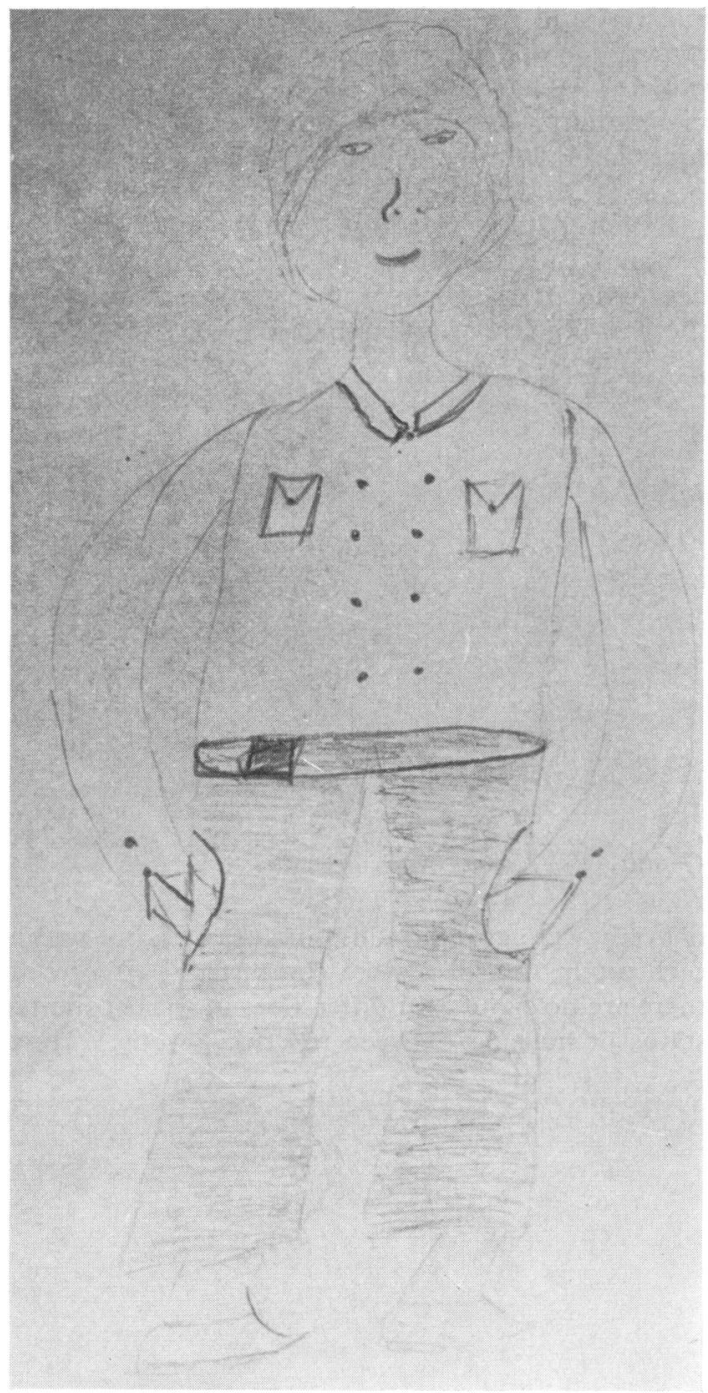

FIG. 4.-Control subject: human figure drawing. ever, from the psychosocial interviews it was found that the control parents coped significantly better $(\mathrm{P}<0.01)$ in handling their children and these children were socially more mature $(P<0.01)$. The index group had significantly less cultural learning opportunities $(P<0.001)$ based on the Deprivation Index of Whiteman and Deutsch (1968). and a greater number of traumatic life experiences $(P<0.001)$.

In the index group there has been a considerable shift from the initial state of marked social deprivation to increased stability, while a slight deterioration has occurred in the controls (Table VIII). Despite a similar number of years at school the achievement of the index group is significantly lower and their 'drop out' rate after leaving school is more than twice as high as the controls.

Special investigations. (i) $X$-rays showed no significant difference in the thickness of the cortex of the skull between the two groups, nor between the left and right hemispheres of each individual. Gyral markings on the skull were not seen. There was no significant difference in the size of the sinuses, some of which were large. (ii) 6 of the index group had abnormal EEGs as did 8 controls.

\section{Discussion}

In 1955 we were the first to formulate the hypothesis that the human brain might be most vulnerable to the effect of undernutrition during the first 2 years of life as this is the period of most rapid growth. Since at that time no interest was shown in the effects of undernutrition on intellectual performance specifically at this age, it was not unreasonable and hardly 'reprehensible' (Dobbing, 1974) to pose the question, 'Does undernutrition during infancy impair brain growth and subsequent intellectual development ?' (Stoch and Smythe, 1963).

Very severely undernourished children were deliberately chosen on the presumption that if these

TABLE VII

Comparisons of BG and HFD in index ${ }^{\star}$ and control subjects matched for NSAIS quotients

\begin{tabular}{|c|c|c|c|c|c|c|}
\hline Case No. & $1 *$ & 2 & $3 \star$ & 4 & $5^{\star}$ & 6 \\
\hline $\begin{array}{l}\text { Age } \\
\text { Full scale quotient } \\
\text { Verbal quotient } \\
\text { Nonverbal quotient } \\
\text { Bender } \\
\text { Human Figure Drawing }\end{array}$ & $\begin{array}{l}16 \cdot 25 \\
46 \\
41 \\
60 \\
7 \\
0\end{array}$ & $\begin{array}{l}17 \cdot 6 \\
46 \\
41 \\
65 \\
0 \\
5\end{array}$ & $\begin{array}{l}16 \cdot 0 \\
73 \\
68 \\
85 \\
5 \\
5\end{array}$ & $\begin{array}{l}15 \cdot 7 \\
75 \\
82 \\
72 \\
0 \\
5\end{array}$ & $\begin{array}{l}15 \cdot 6 \\
53 \\
51 \\
65 \\
10 \\
0\end{array}$ & $\begin{array}{r}16 \cdot 0 \\
51 \\
51 \\
62 \\
0 \\
5\end{array}$ \\
\hline
\end{tabular}


TABLE VIII

Sociodemographic data

\begin{tabular}{|c|c|c|c|c|}
\hline & \multicolumn{2}{|c|}{ Index } & \multicolumn{2}{|c|}{ Control } \\
\hline & Boys (9) & Girls (11) & Boys (9) & Girls (11) \\
\hline
\end{tabular}

grossly undernourished children showed no subsequent intellectual impairment, then nutritional factors could clearly play no significant role in intellectual development. The striking deficits in intellect which, with time, became increasingly apparent have raised many questions of the part played by factors other than nutrition and the nature of the link between the nutritional pathological process and the functioning of the brain.

Controls. The validity of our findings has been questioned on the grounds of the more favourable early environment of subjects in the control group (Scrimshaw and Gordon, 1968). The reason for selecting the control children from a day nursery school-cum-crêche was to try to ensure adequate nutrition in a group of children taken from the lowest socioeconomic subpopulation. With time it has become apparent that the control group did not have optimal nutrition and did not have as marked as enviromental advantage as was originally supposed. The initial gain from the stimulus of nursery school attendance will have evened off after the first 6 months at school. The quality of mothering received by the two groups during infancy was probably not so different. Though the mothers of the index subjects were all negligent, apathetic, and irresponsible, they did not abandon their children but nursed them ineffectually. Control mothers, being in full-time employment, were separated from their children when they were at an average age of 1.3 years. At that time they spent their days in an understaffed crêche but evenings and weekends with the parents. In the index group, because of smaller families, there was more parentchild interaction than in the control group. The high rate of illegitimacy in the index group has been unfavourably compared with the control families, but two of the control girls now have illegitimate children, and none of the index girls. The latest assessment shows that only 5 of the index subjects remain in a less favourable environment than the controls.
There is considerable nutritional as well as other evidence to suggest that the controls were suboptimal. Originally their mean weight was at the 10th centile. Currently their weight and height is low when compared with a random sample of school children of the same age. Their full scale quotient when adjusted by adding $1 \mathrm{SD}$ is still below the expected average range. Only 50\% achieved perceptual maturity as assessed on the BG, and no less than $40 \%$ had abnormal EEGs. From this it appears that had the index group been compared with adequately nourished controls an even more striking difference might well have been shown. Genetic factors are unlikely to have influenced the findings in that no significant difference was found between the parents of the two groups in head circumference, intelligence tests (Raven's Matrices, 1956), and school achievement.

Head circumference. The single most surprising finding is that the mean difference of the head circumference has increased over the 10-year period when difference in mean height decreased.

$\begin{array}{lllll} & 1962 & 1967 & 1972 & \text { Difference } \\ \begin{array}{l}\text { Difference in } \\ \text { mean head } \\ \text { circum- }\end{array} & & & \\ \begin{array}{l}\text { ference } \\ \text { (cm) }\end{array} & 2 \cdot 28 & 2 \cdot 46 & 2 \cdot 79 & +0.51 \\ \text { Height (cm) } & 8.8 & 7.95 & 6.07 & -2.73\end{array}$

As the significance of head circumferences measurements has been questioned (Evans, Moodie, and Hansen, 1971), it is necessary to repeat that it has never been suggested that there is any correlation between head circumference and IQ. What has been stated is that there may be a relation between infantile undernutrition, suboptimal head circumference, and suboptimal brain growth. In fact, from this study it appears that suboptimal head circumference may be the most sensitive physical index of prolonged undernutrition during infancy. 
A close correlation has been found between head circumference and brain weight and protein (DNA) content (Winick and Rosso, 1969). Furthermore, the reduced head circumference in malnourished children accurately reflects the reduced number of cells and reduced lipid content present in their brains (Winick, 1971). While accepting that whole brain DNA content represents the more numerous glial cells better than the number of nerve cells, this must nevertheless represent suboptimal growth.

The increase in head circumference of both groups over the last 5 years is ascribed to increase in skull and scalp thickness. Skull thickness as measured on $x$-rays was fractionally greater in the control group than in the index, but not enough to account for the increasing difference in circumference. While it appears that over the last 5 years there has been some increase in brain mass in the control group greater than that in the index group the skull $x$-rays of both groups were noted for their thickness, for absence of any gyral markings, and in some subjects for abnormally large sinus development, changes typically seen in conditions of defective brain growth.

Psychological test findings. Over the full period of this study the differences between the intelligence scores of the two groups have remained significant, and since the previous intelligence testing was done 5 years ago the difference in full scale quotient has remained unchanged. The deficit in intellectual function appears to be permanent.

Children who experience emotional deprivation during infancy subsequently have poor expressive and reasoning abilities. However, these verbal skills are also affected by the understimulating environment of the lower social class background of both groups in this study. Difference in verbal skills was more marked between the two groups of boys than the girls, the significant fact being the relatively low scores of the control girls. The control boys, who came from a similar social background, were able to overcome to some extent their environmental handicaps and achieved relatively adequate verbal levels. In contrast to other findings (Jensen, 1973; Hertzig et al., 1972) where the underprivileged subpopulation achieved higher verbal than nonverbal scores, in this and in our previous study nonverbal scores were higher than the verbal. This is an unexpected finding in view of their visual-motor perceptual difficulties and may be a reflection of a linguistic gap between the subjects of this study and the subpopulation in which the NSAIS was standardized. The biggest drop over the last 5 years has been in the verbal quotient of the index group, especially the girls. In fact the verbal scores might have been even lower since 6 of the index group performed at or below the floor level of the verbal scale in contrast to 2 of the controls. In the nonverbal subtests all these subjects scored above the floor level, while in Hertzig's series 17 out of 54 failed to achieve the floor level. This difference may be accounted for by the inclusion in the NSAIS of the poorly correlating subtests of Absurdities and Form Board, the only tests which showed no significant differences between any of the groups. The significant differences in the subtests of Pattern Completion and Blocks in the index group point to specific visual perceptual synthetic and analytic disabilities.

The Bender Visual Motor Gestalt Test and Human Form Drawing were used to explore visual motor perception and body concept. The poor test performance found in the index group did not correlate with their intelligence scores. The errors made indicate a deficit in their neurointegrative system, as similar errors are commonly made by children with minimal brain dysfunction. The Bender specifically measures visual-motor perception abilities which are essential for acquiring basic scholastic skills. At the age of 16 five of the index group were at a level fit only for first year instruction at school.

There is no documented evidence that environmental factors, apart from very extensive sensory deprivation, such as blindness, could at this age account for the defects in the visual-motor perception found in the index group. On the contrary, Nissen's study (Bender, 1938) of West African children has shown that native children without previous experience with pencil and paper copy designs with the 'same ability as an average American-born and educated child'. The HFD correlates well with the BG $(r=0 \cdot 7)$. If there is reversibility and catch-up of impaired perceptual functioning this should become apparent on tests based on a developmental scoring system which show improvement with age, but in both the BG and the HFD there was no correlation with age and no support for improvement with time. Of particular value in this 15-year continuous study is that no further maturational perceptual changes are likely to occur and some clarification of the associated disturbance of brain function with the nutritional pathology has been possible.

Catch-up. The concept of catch-up implies that given better feeding after a period of under- 
nutrition, rehabilitation of the effects of undernutrition can be achieved. Feeding and welfare facilities were made available to these subjects, though it was not possible to ensure that they got the food. The fact that there has been catch-up growth in height in the index group does however imply that nutrition has improved. The fact that this occurred at a time when the difference in head circumference has increased supports our original hypothesis that not only is the period of growth spurt important, but also the duration of undernutrition relative to the total period of growth. Timing is important, as catch-up growth may be possible with good nutrition if it occurs within the period of time when growth of that particular structure normally continues. We reject the suggestion that catch-up growth can occur at any time (Evans et al., 1971). There is no evidence that nature's time clock for growth can be significantly altered by nutrition. Teeth appear on a time schedule irrespective of the state of nutrition; the great bulk of brain growth occurs in the later intrauterine stage and during the first 2 years of life, and catch-up is likely to be limited to this period. At the same time, specific facets of brain structure, such as neuronal cell multiplication, may be limited to an even shorter period. As cell multiplication apparently ceases at 6 months of age these early months may be the most critical of all (making the world-wide decline of breast feeding in developing countries possibly disastrous in its implication).

Environmental effect on intelligence performance as against organic brain damage. Undoubtedly the index group suffered from environmental deprivation owing to the higher incidence of illegitimacy, deprivation of learning experience apart from school, poorer parental nurturance, and more personal traumatic experiences. The control group, however, also suffered real disadvantages and over the period of observation the early differences between the two groups have to a considerable extent been eliminated. Difficult as it is to separate environmental from nutritional factors in the poor performance of these children, it does not seem possible that the significantly low head circumference in the index group, the errors in the BG and HFD, and the high incidence of abnormal EEGs in both groups can be explained on any other than an organic basis.

A clearer definition not only of timing and duration of the period of undernutrition but also of specific nutritional deficiencies is required. We have previously suggested (Stoch and Smythe, 1967) that marasmus, occurring as it does at a younger age, is more serious in its effects than kwashiorkor. The subjects of this study were severe cases of marasmus but the majority of subsequent studies have been done on children with kwashiorkor, a less prevalent form of undernutrition, and if energy requirements are less restricted in kwashiorkor this could allow some brain growth to continue at the expense of other body tissues. Furthermore, the effect on intellectual development of little physical activity and of the listlessness which occurs in undernourished children needs to be assessed.

\section{Conclusion}

Over the period of 15-18 years that this group of children have been followed since the initial period of severe marasmic undernutrition during the first year of life, evidence has accumulated of grcss irreversible intellectual impairment, despite improved environmental conditions and improved nutrition as indicated by catch-up in height. The small head circumference, deficits in visual-motor perception, disturbed body concept, and the high incidence of abnormal EEGs, can only be explained on a basis of organic brain dysfunction, dominantly at a central neurointegrative level.

The assistance of Dr. P. M. Leary in reporting on the EEGs, is gratefully acknowledged.

REFERENCES

Bender, L. (1938). A Visual Motor Gestalt Test and its Clinical Use. American Orthopsychiatric Association, New York.

Dobbing, J. J. (1974). The later growth of the brain and its vulnerability. Pediatrics, 53, 2.

Evans, D. E., Moodie, A. D. and Hansen, J. D. L. (1971). Kwashiorkor and intellectual development. South African Medical Fournal, 45, 1413.

Hertzig, M. E., Birch, H. G., Richardson, S. A., and Tizard, J. (1972). Intellectual levels of school children severely malnourished during the first two years of life. Pediatrics, 49,814 .

Jensen, A. R. (1973). Educability and Group Differences. Methuen, London.

Koppitz, E. M. (1964). The Bender Gestalt Test for Young Children. Grune and Stratton, New York.

Koppitz, E. M. (1968). Psychological Evaluation of Children's Human Figure Drawings. Grune and Stratton, New York.

Langeveld, M. J. (1969). The Columbus. Karger, Basel.

National Bureau of Education and Social Research. (1964). New South African Individual Scale. Department of Education, Arts and Science, Pretoria.

Raven, J. C. (1956). Coloured Progressive Matrices. Lewis, London.

Robertson, I. (1961). Weight charts of coloured infants and preschool children. South African Medical fournal, 35, 466.

Scrimshaw, N. S., and Gordon, J. E. (Eds.). Malnutrition, Learning, and Behaviour, p. 278. M.I.T. Press, Cambridge, Massachusetts.

Stoch, M. B., and Smythe, P. M. (1963). Does undernutrition during infancy inhibit brain growth and subsequent intellectual development? Archives of Disease in Childhood, 38, 546.

Stoch, M. B., and Smythe, P. M. (1967). The effect of undernutrition during infancy on subsequent brain growth and intellectual development. South African Medical fournal, 41, 1027. 
Whiteman, M., and Deutsch, M. (1968). Social disadvantages as related to intellective and language development. Social Class, Race and Psychological Development, p. 86. Ed. by M. Deutsch, I. Katz, and A. R. Jensen. Holt, Rinehart and Winston, New York.

Winick, M. (1971). Cellular growth during early malnutrition. Pediatrics, 47, 969.

Winick, M. and Rosso, P. (1969). Head circumference and cellular growth of the brain in normal and marasmic children. Fournal of Pediatrics, 74, 774.

Correspondence to Professor P. M. Smythe, Department of Paediatrics and Child Health, University of Natal Medical School, P.O. Box 39, Congella 4013. Natal, South Africa. 